\title{
Altered peripheral lymphocyte subsets in untreated systemic lupus erythematosus patients with infections
}

\author{
Zhimin Lu (iD), Jing Li (iD), Juan Ji (iD, Zhifeng Gu (iD, and Zhanyun Da (i)
}

Department of Rheumatology, Affiliated Hospital of Nantong University, Nantong, People's Republic of China

\begin{abstract}
The leading cause of death in systemic lupus erythematosus (SLE) patients is infection. The objective of this study was to evaluate the distribution of lymphocyte subsets in untreated SLE patients with infections. This was a cross-sectional study. Data from January 2017 to May 2018 were collected. Flow cytometry was used to measure the peripheral lymphocyte subsets including $\mathrm{CD} 3^{+} \mathrm{T}$ cells, $\mathrm{CD} 4^{+} \mathrm{T}$ cells, $\mathrm{CD} 8^{+} \mathrm{T}$ cells, $\mathrm{CD} 19^{+} \mathrm{B}$ cells, CD3 ${ }^{-\mathrm{CD}} 16+\mathrm{CD} 56 \mathrm{NK}$ cells, and $\mathrm{CD} 3^{+} \mathrm{CD} 16+\mathrm{CD} 56 \mathrm{NKT}$ cells in 25 healthy controls and 52 treatment-naive SLE patients, among whom 13 were complicated with infections. Association between the lymphocyte subsets and infections was further analyzed. SLE patients with infections $(n=13)$ showed a significantly higher incidence rate of fever ( 84.6 vs $28.2 \%$ ) and serositis ( 84.6 vs $23.1 \%$ ), increased level of erythrocyte sedimentation rate $(60.5 \pm 30.1$ vs $37.4 \pm 27.1 \mathrm{~mm} / \mathrm{h})$, serum C-reactive protein (CRP) $(102.7 \pm 94.9$ vs $9.4 \pm 14.9 \mathrm{mg} / \mathrm{L})$, procalcitonin (PCT) $(1.07 \pm 0.08$ vs $0.16 \pm 0.13 \mu \mathrm{g} / \mathrm{L})$, and lower blood hemoglobin $(\mathrm{Hb})(93.0 \pm 20.5 \mathrm{vs} 110.4 \pm 16.0 \mathrm{~g} / \mathrm{L})$ level compared with noninfection patients $(n=39)($ all $P<0.05)$. In comparison with non-infectious SLE patients $(387.9 \pm 261.6 / \mu L), C D 4^{+} T$ cells count decreased significantly in infectious SLE patients $(217.8 \pm 150.4 / \mu \mathrm{L})(\mathrm{P}<0.05)$, and it was negatively correlated with infectionrelated indicators including PCT $(r=-0.573, P=0.041)$ and $C R P(r=-0.596, P=0.032)$ levels. Our findings suggested that abnormalities of peripheral lymphocyte subsets were related to the immune disorder of lupus itself, regardless of immunosuppressive treatment. Monitoring lymphocyte subsets, especially $\mathrm{CD} 4^{+} \mathrm{T}$ cells, may be helpful for identifying the presence of infection in SLE patients.
\end{abstract}

Key words: Systemic lupus erythematosus; Lymphocyte subsets; Infection; C-reactive protein; Procalcitonin

\section{Introduction}

Systemic lupus erythematosus (SLE) is a typical autoimmune disease characterized by complex immunological abnormalities and highly diverse clinical manifestations. Patients with SLE are often in a major immunosuppressive state caused by the immune disorder and application of immunosuppressive agents. Infectious complications, especially of the skin, and respiratory and urinary systems, develop in up to $50 \%$ of SLE patients $(1,2)$, and serious infection remains a main cause of hospitalization and mortality $(2,3)$. Infectious pathogens have also been shown to play a role in the pathogenesis of and increased disease activity in SLE (4).

It has been demonstrated that immune disturbances of lupus itself and use of immunosuppressive drugs are both important risk factors for infections in SLE patients, but the underlying mechanism remains elusive $(5,6)$. It is not clear whether the increased burden of infections seen in SLE patients relates to the immune disorder underlying the disease, treatment with immunosuppressive agents, or the interplay between these factors (6).
Since there is scant evidence of infection analysis of new-onset SLE patients without treatment, the main aim of the present study was to address whether inherent immune disturbances are an independent risk factor for the development of infections. As we know, peripheral lymphocytes play an important role in anti-infection immune response and abnormal status accounts for a bad ending in infection diseases (7). We mainly investigated the major lymphocyte subsets in untreated SLE patients and analyzed their relation to infections. As a secondary aim, we explored some credible makers for identifying the presence of infection in SLE patients.

\section{Material and Methods}

\section{Patients and controls}

Fifty-two SLE patients with no history of corticosteroids or immunosuppressive drug use were recruited from the Department of Rheumatology of the Affiliated Hospital of Nantong University from January 2017 to May 2018.

Correspondence: Zhanyun Da: <dazhanyun@163.com> | Zhifeng Gu: <guzf@ntu.edu.cn> 
These SLE patients had not taken glucocorticoids or immunosuppressive agents when they went to our hospital for diagnosis and treatment. The SLE patients fulfilled the 1997 SLE classification criteria revised by American College of Rheumatology (8). Twenty-five age- and sexmatched healthy controls $(\mathrm{HC})$ were enrolled in this study. Patients complicated with tumor or other autoimmune diseases were excluded. This cross-sectional study was approved by the Ethics Committee of the Affiliated Hospital of Nantong University, and written informed consent was obtained from all subjects. Infection was considered definite or probable according to culture results. A definite bacterial infection was diagnosed if an organism was identified on culture or microscopy. In the absence of a pathogenic bacteria being identified, a probable bacterial infection diagnosis was made on the basis of a combination of clinical findings, review of imaging studies, laboratory finding such as white blood cell count, and a response to only antibiotic therapy.

The baseline demographic and clinical data were collected from hospital records and reviewed by experienced physicians. The data included age, gender, and duration. Routine laboratory investigation included white blood cell (WBC), blood hemoglobin $(\mathrm{Hb})$, blood platelet (PLT), erythrocyte sedimentation rate (ESR), serum levels of C-reactive protein (CRP), procalcitonin (PCT), serum concentrations of complement factors $\mathrm{C} 3$ and $\mathrm{C} 4$, antidsDNA using an immunoblotting technique, serum lgG, $\lg \mathrm{M}$, and $\lg \mathrm{A}$, and 24-h urinary protein levels.

Disease activity was measured using the Systemic Lupus Erythematosus Disease Activity Index (SLEDAI) score according to the medical records (9).

\section{Sample collection and preparation}

Peripheral blood of SLE patients and healthy controls was collected. The blood of SLE patients was collected prior to therapy with glucocorticoids and immunosuppressive agents. Four milliliters of heparinized blood was diluted with the same volume of phosphate-buffered saline (PBS). Peripheral blood mononuclear cells (PBMCs) were prepared by Ficoll-Plaque (Pharmacia, Sweden) density gradient centrifugation $\left(400 \mathrm{~g}, 18^{\circ} \mathrm{C}, 30 \mathrm{~min}\right)$, washed in RPMI 1640 culture medium (Gibco, USA) twice, and then resuspended at a concentration of $2 \times 10^{6} \mathrm{cells} / \mathrm{mL}$.

A typical panel of markers used to identify the major subset of lymphocytes included CD3, CD4, CD8, CD19, and CD16+56. Freshly isolated and cultured PBMCs were suspended in PBS. For the staining of surface antigens, cells were incubated with FITC-conjugated antiCD3, APC-conjugated anti-CD4, PE-conjugated anti-CD8, APC-conjugated anti-CD19, and PE-conjugated antiCD16 + 56 (all from BD Bioscience, USA). Mouse antihuman FITC-, PE-, and APC-conjugated IgG1 were used as isotype controls. All cell samples were assayed by a FACSCalibur flow cytometer (BD Bioscience) and the acquired data were further analyzed using FCS Express
V3 (De Novo Software, Canada) analysis software. Flow cytometric results are reported as positive percentages. Trucount tubes (BD Bioscience) were used to determine the absolute number. The percentages and counts of the lymphocyte subsets including $\mathrm{CD} 3^{+} \mathrm{T}$ cells, $\mathrm{CD} 4^{+} \mathrm{T}$ cells, $\mathrm{CD}^{+} \mathrm{T}$ cells, CD19 ${ }^{+} \mathrm{B}$ cells, CD3 $\mathrm{CD} 16+\mathrm{CD} 56 \mathrm{NK}$ cells, and $\mathrm{CD}^{+}$CD16 + CD56NKT cells, as well as CD4/CD8 ratio were measured.

\section{Statistical analysis}

All data were analyzed using SPSS version 17.0 software (IBM, USA). Means \pm SE or interquartile ranges are reported for numeric values with normal and nonnormal distribution, respectively. Categorical variables are reported as frequency and percentage. Clinical characteristics of infection and non-infection SLE patients were compared using Student's t-test, Wilcoxon Rank-Sum test, or the chi-squared test, as appropriate. Pearson correlation analysis was performed to evaluate the correlation between variables of peripheral lymphocyte subsets and infection-related indicators in SLE patients with infection. $P$ values $<0.05$ were considered statistically significant.

\section{Results}

\section{Clinical characteristics}

A total of 52 patients diagnosed with SLE were included; 13 patients were complicated with infections. Patient characteristics are reported in Table 1. Classification of infections were as follows: pneumonia $(n=6)$, upper respiratory tract infection $(n=5)$, gastrointestinal tract infection $(n=1)$, and septicemia $(n=1)$. The median age of SLE patients with infection was $31.0 \pm 9.6$ years (female/male: $12 / 1$ ) and that of non-infection SLE patients was $36.4 \pm 13.5$ years (female/male: $37 / 3)(P>0.05)$. The mean age of $\mathrm{HC}$ was $32.3 \pm 8.9$ years (female/male: $22 / 3$ ). Disease activity was calculated using SLEDAI score. There was no significant difference of the mean SLEDAI score between the infection and non-infection group $(12.3 \pm 3.4$ vs $10.8 \pm 5.3, \mathrm{P}>0.05)$. The average disease duration of the infection group was $6.9 \pm 13.0$ months, which was significantly shorter than that in the non-infection group $(19.8 \pm 29.4$ months $)(P<0.05)$. SLE patients with infections showed significantly a higher incidence rate of fever ( 84.6 vs $28.2 \%$ ) and serositis (84.6 vs $23.1 \%$ ) compared with non-infection patients (both $\mathrm{P}<0.05$ ). There were no differences in the incidence rates of new rashes, arthritis, nephritis, or central nervous system, gastrointestinal or cardiac involvement between the two groups.

Compared with non-infection patients, SLE patients with infection had a significantly higher serum level of ESR, CRP, and PCT (all $\mathrm{P}<0.05$ ), the mean $\mathrm{Hb}$ level of infection patients was significantly lower $(P<0.05)$. There were no significant differences in the levels of WBC, PLT, complement, antiantibodies, or urinary protein levels between the two groups. 
Table 1. Characteristics of untreated systemic lupus erythematosus (SLE) patients with and without infection.

\begin{tabular}{|c|c|c|c|}
\hline Features & Non-infection $(n=39)$ & Infection $(n=13)$ & $P$ \\
\hline Age (years) & $36.4 \pm 13.5$ & $31.0 \pm 9.6$ & 0.192 \\
\hline Gender (F / M) & $37 / 3$ & $12 / 1$ & 1.000 \\
\hline Disease duration (months) & $19.8 \pm 29.4$ & $6.9 \pm 13.0$ & 0.035 \\
\hline \multicolumn{4}{|l|}{ Clinical manifestations } \\
\hline Fever & $11(28.2 \%)$ & $11(84.6 \%)$ & $<0.001$ \\
\hline New rashes & $28(71.8 \%)$ & $6(46.2 \%)$ & 0.178 \\
\hline Arthritis & $16(41.0 \%)$ & $3(23.1 \%)$ & 0.406 \\
\hline Serositis & $9(23.1 \%)$ & $11(84.6 \%)$ & $<0.001$ \\
\hline Nephritis & $12(30.8 \%)$ & $5(38.5 \%)$ & 0.864 \\
\hline CNS involvement & $2(5.1 \%)$ & $0(0 \%)$ & 1.000 \\
\hline Gastrointestinal involvement & $4(10.3 \%)$ & $1(7.7 \%)$ & 1.000 \\
\hline Cardiac involvement & $1(2.6 \%)$ & $1(7.7 \%)$ & 0.434 \\
\hline \multicolumn{4}{|l|}{ Laboratory data } \\
\hline ANA antibody positive & $39(100 \%)$ & $13(100 \%)$ & 1.000 \\
\hline Anti-SSA antibody positive & $28(71.8 \%)$ & $9(69.2 \%)$ & 1.000 \\
\hline Anti-SSB antibody positive & $10(25.6 \%)$ & $3(23.1 \%)$ & 1.000 \\
\hline Anti-SM antibody positive & $16(41.0 \%)$ & $7(53.8 \%)$ & 0.420 \\
\hline Anti-dsDNA antibody & $374.1 \pm 321.3$ & $515.0 \pm 358.6$ & 0.204 \\
\hline AnuA & $98.2 \pm 85.6$ & $119.4 \pm 95.1$ & 0.489 \\
\hline $\operatorname{WBC}\left(\times 10^{9} / \mathrm{L}\right)$ & $4.6 \pm 2.2$ & $5.0 \pm 3.0$ & 0.541 \\
\hline $\mathrm{Hb}(\mathrm{g} / \mathrm{L})$ & $110.4 \pm 16.0$ & $93.0 \pm 20.5$ & 0.003 \\
\hline $\operatorname{PLT}\left(\times 10^{9} / \mathrm{L}\right)$ & $185.4 \pm 85.4$ & $186.6 \pm 106.1$ & 0.968 \\
\hline $\mathrm{ESR}(\mathrm{mm} / \mathrm{h})$ & $37.4 \pm 27.1$ & $60.5 \pm 30.1$ & 0.013 \\
\hline CRP (mg/L) & $9.4 \pm 14.9$ & $102.7 \pm 94.9$ & 0.004 \\
\hline PCT $(\mu \mathrm{g} / \mathrm{L})$ & $0.16 \pm 0.13$ & $1.07 \pm 0.08$ & 0.001 \\
\hline $\lg G(g / L)$ & $17.9 \pm 9.4$ & $20.9 \pm 6.5$ & 0.335 \\
\hline $\lg A(g / L)$ & $2.6 \pm 0.9$ & $3.0 \pm 1.3$ & 0.275 \\
\hline $\lg M(g / L)$ & $1.3 \pm 0.7$ & $1.5 \pm 1.2$ & 0.679 \\
\hline C3 (g/L) & $0.45 \pm 0.21$ & $0.41 \pm 0.21$ & 0.616 \\
\hline C4 (g/L) & $0.087 \pm 0.057$ & $0.092 \pm 0.071$ & 0.812 \\
\hline 24-h urinary protein $(\mathrm{g})$ & $1.0 \pm 2.1$ & $1.4 \pm 1.2$ & 0.565 \\
\hline SLEDAI & $10.8 \pm 5.3$ & $12.3 \pm 3.4$ & 0.348 \\
\hline
\end{tabular}

Data are reported as means $\pm S D$ or number and percent within parentheses. CNS: central nervous system; ANA: antinuclear antibodies; dsDNA: double-stranded DNA; AnuA: anti-nucleosome antibodies; WBC: white blood cells; Hb: blood hemoglobin; PLT: blood platelets; ESR, erythrocyte sedimentation rat; CRP: serum levels of C-reactive protein; PCT: procalcitonin; Ig: immunoglobulin, C3: complement 3; C4: complement 4; SLEDAl: systemic lupus erythematosus disease activity index. Significant differences $(\mathrm{P}<0.05)$ are shown in bold. Student's $t$-test, Wilcoxon Rank-Sum test, or the chi-square test were used as appropriate.

\section{Distribution of lymphocyte subsets}

The lymphocyte subset results of these three groups including $\mathrm{HC}$, non-infection SLE patients, and infection SLE patients are summarized in Table 2. In comparison with $\mathrm{HC}$, the absolute number of $\mathrm{CD}^{+} \mathrm{T}$ cells, CD4 ${ }^{+} \mathrm{T}$ cells, $\mathrm{CD} 8^{+} \mathrm{T}$ cells, NK cells, and NKT cells were significantly downregulated in SLE patients with and without infection (all $\mathrm{P}<0.05)$. The CD4/CD8 ratio was lower in the two SLE patient groups compared with $\mathrm{HC}$ (both $\mathrm{P}<0.05$ ).

This study confirmed that $\mathrm{CD} 4^{+} \mathrm{T}$ cells in peripheral blood decreased significantly in infectious SLE patients compared to non-infectious SLE patients $(217.8 \pm 150.4$ vs $387.9 \pm 261.6 / \mu \mathrm{L}, \mathrm{P}<0.05$, Figure $1 \mathrm{~A}$ ). The peripheral $\mathrm{CD}^{+} \mathrm{T}$ cells were marginally down-regulated in SLE patients with infections $(531.9 \pm 262.6$ vs $830.6 \pm 510.9 / \mu \mathrm{L}, \mathrm{P}=0.05$, Figure1B).

In addition, we observed a similar tendency in absolute number of NK cells, but it failed to reach statistical significance.

\section{Correlation between peripheral $\mathrm{CD}^{+} \mathrm{T}$ cells}

Correlation analysis showed that in infectious SLE patients, the absolute number of peripheral $C D 4^{+} \mathrm{T}$ cells 
Table 2. Distribution of lymphocyte subsets in untreated systemic lupus erythematosus (SLE) patients with and without infection.

\begin{tabular}{|c|c|c|c|c|c|c|}
\hline & \multirow{2}{*}{$\begin{array}{l}\text { Healthy controls } \\
\qquad(n=25)\end{array}$} & \multirow{2}{*}{$\begin{array}{l}\text { Non-infection } \\
\qquad(n=39)\end{array}$} & \multirow{2}{*}{$\begin{array}{l}\text { Infection } \\
(n=13)\end{array}$} & \multicolumn{3}{|c|}{$\mathrm{P}$} \\
\hline & & & & $\begin{array}{c}\text { Non-infection vs } \\
\text { HC }\end{array}$ & $\begin{array}{c}\text { Infection vs } \\
\mathrm{HC}\end{array}$ & $\begin{array}{c}\text { Non-infection vs } \\
\text { infection }\end{array}$ \\
\hline Lymphocyte & $2031.6 \pm 537.6$ & $1114.2 \pm 625.5$ & $745.2 \pm 372.3$ & 0.000 & 0.000 & 0.051 \\
\hline $\mathrm{CD}^{+} \mathrm{T}(\%)$ & $75.4 \pm 3.9$ & $73.8 \pm 9.6$ & $73.6 \pm 11.7$ & 0.366 & 0.605 & 0.952 \\
\hline $\mathrm{CD}^{+}{ }^{+} \mathrm{T}(\%)$ & $42.9 \pm 4.7$ & $34.3 \pm 9.9$ & $28.9 \pm 8.8$ & 0.000 & 0.000 & 0.085 \\
\hline $\mathrm{CD}^{+} \mathrm{T}(\%)$ & $31.4 \pm 7.5$ & $36.6 \pm 10.1$ & $40.5 \pm 13.9$ & 0.029 & 0.041 & 0.272 \\
\hline $\mathrm{CD}^{+} 9^{+} \mathrm{B}(\%)$ & $10.8 \pm 4.4$ & $18.5 \pm 9.4$ & $19.4 \pm 10.9$ & 0.000 & 0.017 & 0.783 \\
\hline NK (\%) & $13.4 \pm 4.9$ & $6.0 \pm 3.7$ & $5.0 \pm 4.4$ & 0.000 & 0.000 & 0.421 \\
\hline NKT (\%) & $4.8 \pm 1.7$ & $3.31 \pm 2.26$ & $3.92 \pm 2.44$ & 0.011 & 0.262 & 0.520 \\
\hline $\mathrm{CD}^{+} \mathrm{T}(\mu \mathrm{L})$ & $1536.3 \pm 443.1$ & $830.6 \pm 510.9$ & $531.9 \pm 262.6$ & 0.000 & 0.000 & 0.05 \\
\hline $\mathrm{CD}^{+} \mathrm{T}(\mu \mathrm{L})$ & $870.1 \pm 248.1$ & $387.9 \pm 261.6$ & $217.8 \pm 150.4$ & 0.000 & 0.000 & 0.031 \\
\hline $\mathrm{CD}^{+} \mathrm{T}(\mu \mathrm{L})$ & $645.1 \pm 249.5$ & $415.7 \pm 327.6$ & $281.1 \pm 151.7$ & 0.004 & 0.000 & 0.161 \\
\hline $\mathrm{CD}_{19}^{+} \mathrm{B}(\mu \mathrm{L})$ & $218.3 \pm 102.3$ & $203.8 \pm 146.9$ & $162.5 \pm 137.4$ & 0.667 & 0.165 & 0.378 \\
\hline NK $(\mu \mathrm{L})$ & $267.9 \pm 111.9$ & $62.2 \pm 44.9$ & $36.5 \pm 36.3$ & 0.000 & 0.000 & 0.068 \\
\hline NKT $(\mu \mathrm{L})$ & $100.7 \pm 55.6$ & $36.6 \pm 26.7$ & $23.2 \pm 26.7$ & 0.000 & 0.001 & 0.188 \\
\hline CD4/8 & $1.4 \pm 0.6$ & $1.03 \pm 0.47$ & $0.84 \pm 0.45$ & 0.001 & 0.001 & 0.196 \\
\hline
\end{tabular}

Data are reported as means \pm SD. Significant differences are shown in bold type (Student's $t$-test). HC: healthy control.
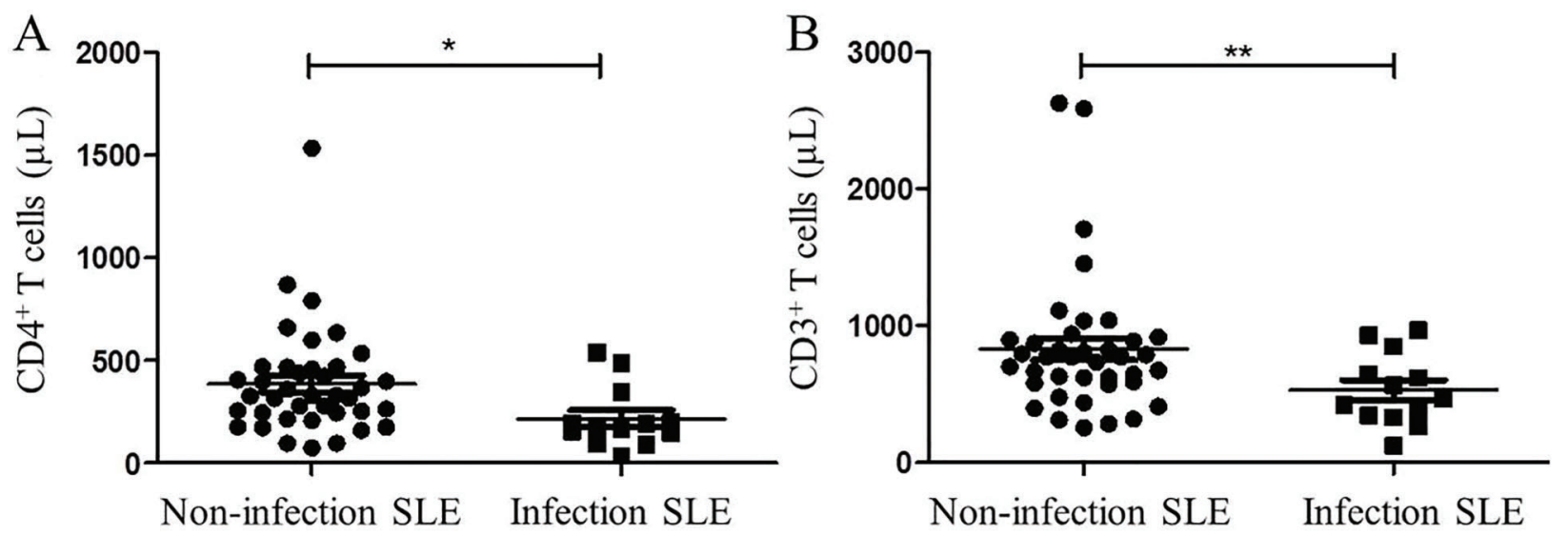

Figure 1. Distribution of (A) CD4 + and (B) CD3 + T cell numbers between the two groups of systemic lupus erythematosus (SLE) patients. ${ }^{*} \mathrm{P}<0.05,{ }^{* *} \mathrm{P}=0.05$ (Student's $t$-test).

was negatively correlated with serum PCT $(r=-0.573, \mathrm{P}=$ 0.041 , Figure $2 A)$ and $C R P(r=-0.596, P=0.032$, Figure $2 B)$. No significant correlation was found between peripheral $\mathrm{CD} 4^{+} \mathrm{T}$ cells with conventional inflammatory markers of ESR.

\section{Discussion}

SLE is a heterogeneous disease characterized by highly diverse clinical manifestations and complications. Infection complications are known to be a major cause of hospitalization and mortality in SLE although the five-year survival rate in SLE has dramatically increased recently due to earlier diagnosis $(1-3,10)$.

In terms of infection complications, Danza and RuizIrastorza (11) reported that disease activity, high anti-DNA titers, low complement levels, nephritis, leucopenia, prednisone doses over 7.5-10 mg/day, and high doses of methylprednisolone and cyclophosphamide were wellrecognized risk factors for infection. However, a study from a multiethnic lupus cohort showed that specific TNF variants and leukopenia influenced the risk of developing 


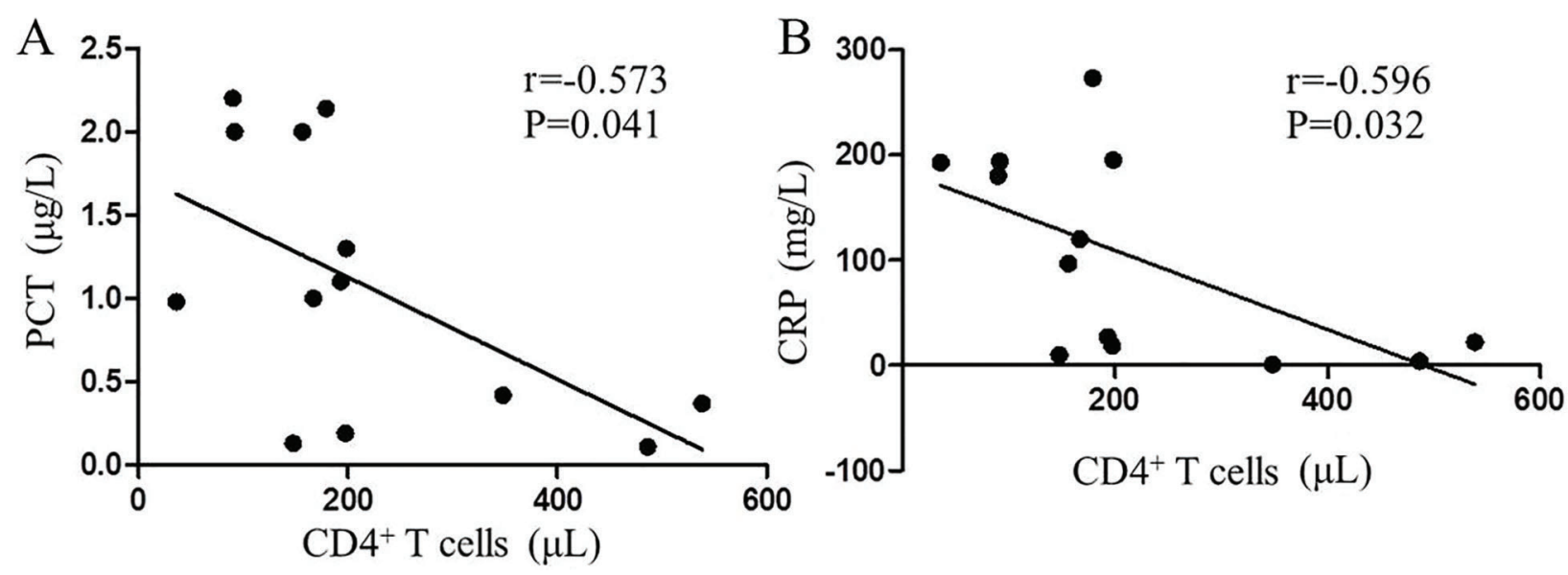

Figure 2. Associations of peripheral CD4 + T cells with (A) procalcitonin (PCT) and (B) C-reactive protein (CRP) in infectious systemic lupus erythematosus (SLE) patients. Data are reported as absolute number of peripheral $\mathrm{CD} 4^{+} \mathrm{T}$ cells $(\mu \mathrm{L})$. Pearson correlation analysis was used for statistical analyses.

pneumonia, regardless of immunosuppressive therapy (12). Research from the Hospital Universitario de Santander suggested that anemia, lymphopenia, hypocomplementemia, and especially the activity of the disease are risk factors for invasive fungal infections in SLE patients (13). In addition, Balbi et al. (14) reported that SLE patients with nephritis and high cumulative doses of corticosteroids may be more prone to developing tuberculosis, especially in endemic countries.

Multivariate analysis identified that SLE flare was an independent predictor of infection-related mortality among SLE patients, while immunosuppressive medications and corticosteroids were not risk factors (2). Discrepancy in the results of these studies may be explained by differences in treatment regimen, as many SLE patients investigated in the majority of previous studies had already been treated with long-time and high doses of immunosuppressive agents, which may influence immune responses.

It is not certain whether the increased rate of infections itself in SLE patients relates to inherent immune disturbances or the relevant medicine given for disease control. To investigate the important role of disease activity itself and inherent abnormal immune status in infection susceptibility in SLE patients, this study analyzed the distribution of lymphocyte subsets in patients with no glucocorticoid or immunosuppressive agent therapy as well as its correlation with infections.

It is well known that the imbalance of activated lymphocyte subsets correlates with the development of SLE $(15,16)$. In SLE patients, the most common changes in lymphocyte subsets are a reduction of $\mathrm{CD} 4^{+} \mathrm{T}$ cells and imbalance of CD4/CD8 ratio $(16,17)$. Boomer et al. (7) observed extensive depletion of splenic CD4, CD8, and HLA-DR cells in patients who died from active severe sepsis, suggesting that internal immune immunosuppressive status accounts for a bad ending, just as materialist dialectics holds "external factors play a role only through internal factors".

There are only a few reports on lymphocyte subsets comparisons between SLE patients with and without infection, especially in untreated patients. Wolfe and Peacock described that lymphopenia and low $\mathrm{CD} 4{ }^{+} \mathrm{T}$ cell count are risk factors of pneumocystis pneumonia in connective tissue diseases (18). Wu et al. (19) reported that the $\mathrm{CD} 4{ }^{+} \mathrm{T}$ cell number and the CD4/CD8 ratio as well as immunoglobulin G level were lower in SLE patients with infection than in those without infection. It is not clear whether decreased $\mathrm{CD}^{+} \mathrm{T}$ cell number and CD4/CD8 ratio relate to the nature of the autoimmune disease or the immunosuppressive agents.

To exclude the influence by the immunosuppressive agents, we enrolled new-onset SLE patients untreated with corticosteroids or immunosuppressive drugs. In our study, we observed that the absolute number of $\mathrm{CD}^{+} \mathrm{T}$ cells, CD4 ${ }^{+} \mathrm{T}$ cells, CD8 ${ }^{+} \mathrm{T}$ cells, NK cells, and NKT cells were remarkably down-regulated in SLE patients compared with $\mathrm{HC}$, which is consistent with previous studies $(16,17)$. As we know, antibody production by $B$ cells requires help from $\mathrm{CD} 4{ }^{+} \mathrm{T}$ cells, so defects in CD4 ${ }^{+} \mathrm{T}$ cells may lead to severe immunodeficiencies. As no immunosuppressive agent was used, we presumed that the altered $\mathrm{CD} 4^{+} \mathrm{T}$ cells related to the nature of the autoimmune disease and the infections. Further studies should expand the group numbers to perform a further multivariate analysis to search for factors related to CD4 + T cell numbers.

On the other hand, current evidence supports the hypothesis that infections may play the role of environmental triggers of various autoimmune diseases in genetically prone individuals $(4,20)$. Infectious pathogens in the 13 infectious SLE patients may play a role in the progress of these genetically predisposed individuals. We supposed the infectious SLE patients had significantly shorter 
disease duration partly due to the trigger of the infectious pathogens. The patients with infection showed a significantly higher incidence rate of fever. The severe clinical manifestations such as fever may drive patients to see doctors. As a result, the patients may be treated earlier and have shorter disease duration.

Due to an abnormal immunological response, the clinical manifestations of the infections can be atypical. Therefore, careful inspection and monitoring are warranted to avoid misdiagnosis. Some studies reported CRP and PCT levels were higher in infection than flare in SLE patients $(21,22)$. A meta-analysis showed that PCT levels are significantly higher in Asian SLE patients with infection (23). Our data also showed that both CRP and PCT levels were higher in SLE patients with infection. We further analyzed the correlation between peripheral $\mathrm{CD}^{+} \mathrm{T}$ cells and infectionrelated indicators in infectious SLE patients. As shown in Figure 2, peripheral $\mathrm{CD}^{+} \mathrm{T}$ cell count was negatively correlated with serum PCT and CRP.

In our study, we verified that SLE patients with $\mathrm{CD} 4^{+} \mathrm{T}$ cell depletion were more prone to develop infections. Considering the individual limitations of each biomarker, we propose the use of these indices together. Clinical testing for lymphocyte subsets is potentially useful for identifying the presence of infection in SLE patients, which may allow physicians to have a more accurate diagnosis.

Our study had several limitations. One of the main limitations was that this study was performed in a

\section{References}

1. Hurd K, Barnabe C. Mortality causes and outcomes in Indigenous populations of Canada, the United States, and Australia with rheumatic disease: A systematic review. Semin Arthritis Rheum 2018; 47: 586-592, doi: 10.1016/ j.semarthrit.2017.07.009.

2. Teh CL, Wan SA, Ling GR. Severe infections in systemic lupus erythematosus: disease pattern and predictors of infection-related mortality. Clin Rheumatol 2018; 37: 20812086, doi: 10.1007/s10067-018-4102-6.

3. Fei Y, Shi X, Gan F, Li X, Zhang W, Li M, et al. Death causes and pathogens analysis of systemic lupus erythematosus during the past 26 years. Clin Rheumatol 2014; 33: 57-63, doi: 10.1007/s10067-013-2383-3.

4. Doaty S, Agrawal H, Bauer E, Furst DE. Infection and lupus: which causes which? Curr Rheumatol Rep 2016; 18: 13, doi: 10.1007/s11926-016-0561-4.

5. Chen HL, Shen LJ, Hsu PN, Shen CY, Hall SA, Hsiao FY. Cumulative burden of glucocorticoid-related adverse events in patients with systemic lupus erythematosus: findings from a 12-year longitudinal study. J Rheumatol 2018; 45: 83-89, doi: 10.3899/jrheum.160214.

6. Feldman $\mathrm{CH}$, Hiraki LT, Winkelmayer WC, Marty FM, Franklin JM, Kim SC, et al. Serious infections among adult Medicaid beneficiaries with systemic lupus erythematosus and lupus nephritis. Arthritis Rheumatol 2015; 67: 15771585, doi: 10.1002/art.39070. single center. Also, the number of patients was small because of the selection criterion of untreated SLE patients. In addition, lymphocyte subsets were evaluated only once after admission and no follow-up was conducted. Another limitation was the heterogeneity of infections and the criteria for diagnosing different types of infections.

In summary, our findings suggested that abnormalities of the CD4 ${ }^{+} \mathrm{T}$ cell subset related to the nature of the autoimmune disease might make the patient more susceptible to infectious pathogens, regardless of treatment with immunosuppressive agents. In addition, CD4 ${ }^{+} \mathrm{T}$ cell count negatively correlated with infection-related indicators. Monitoring lymphocyte subsets, especially $\mathrm{CD} 4^{+} \mathrm{T}$ cells, may be helpful for identifying the presence of infection in SLE patients.

\section{Acknowledgments}

We thank all SLE patients and healthy controls involved in the study. Funding was received from The National Natural Science Foundation of China (Grant Nos. 81601410, 81871278, 81671616, and 81801610); Special Fund for Clinical Medicine, Nantong Science and Technology Bureau (Grant Nos. HS2014071 and HS2016003); Jiangsu Provincial Commission of Health and Family Planning (Grant No. H201623); and Nantong 226 Talents Project (Grant No. 2017-13)

7. Boomer JS, To K, Chang KC, Takasu O, Osborne DF, Walton $\mathrm{AH}$, et al. Immunosuppression in patients who die of sepsis and multiple organ failure. JAMA 2011; 306: 25942605, doi: 10.1001/jama.2011.1829.

8. Hochberg MC. Updating the American College of Rheumatology revised criteria for the classification of systemic lupus erythematosus. Arthritis Rheum 1997; 40: 1725, doi: 10.1002/ art.1780400928.

9. Bombardier C, Gladman DD, Urowitz MB, Caron D, Chang $\mathrm{CH}$. Derivation of the SLEDAI. A disease activity index for lupus patients. The Committee on Prognosis Studies in SLE. Arthritis Rheum 1992; 35: 630-640, doi: 10.1002/art.1780 350606.

10. Zhan Z, Lao M, Su F, Chen D, Liang L, Yang X. Hospitalacquired infection in patients with systemic lupus erythematosus: a case-control study in a southern Chinese population. Clin Rheumatol 2018; 37: 709-717, doi: 10.1007/ s10067-017-3919-8.

11. Danza A, Ruiz-Irastorza G. Infection risk in systemic lupus erythematosus patients: susceptibility factors and preventive strategies. Lupus 2013; 22: 1286-1294, doi: 10.1177/0961 203313493032.

12. Kinder BW, Freemer MM, King TE Jr, Lum RF, Nititham J, Taylor K, et al. Clinical and genetic risk factors for pneumonia in systemic lupus erythematosus. Arthritis Rheum 2007; 56: 2679-2686, doi: 10.1002/art.22804. 
13. Santamaría-Alza Y, Sánchez-Bautista J, Fajardo-Rivero JF, Figueroa CL. Invasive fungal infections in Colombian patients with systemic lupus erythematosus. Lupus 2018; 27: 11161122, doi: $10.1177 / 0961203318763743$.

14. Balbi GGM, Machado-Ribeiro F, Marques CDL, Signorelli F, Levy RA. The interplay between tuberculosis and systemic lupus erythematosus. Curr Opin Rheumatol 2018; 30: 395402, doi: 10.1097/BOR.0000000000000493.

15. He J, Zhang $X$, Wei $Y$, Sun X, Chen $Y$, Deng J, et al. Lowdose interleukin-2 treatment selectively modulates CD4 (+) $T$ cell subsets in patients with systemic lupus erythematosus. Nat Med 2016; 22: 991-993, doi: 10.1038/nm.4148.

16. Erkeller-Yüsel F, Hulstaart F, Hannet I, Isenberg D, Lydyard P. Lymphocyte subsets in a large cohort of patients with systemic lupus erythematosus. Lupus 1993; 2: 227-231, doi: 10.1177/096120339300200404.

17. Xue C, Lan-Lan W, Bei C, Jie C, Wei-Hua F. Abnormal Fas/ FasL and caspase-3-mediated apoptotic signaling pathways of $\mathrm{T}$ lymphocyte subset in patients with systemic lupus erythematosus. Cell Immunol 2006; 239: 121-128, doi: 10.1016/ j.cellimm.2006.05.003.

18. Wolfe RM, Peacock JE Jr. Pneumocystis pneumonia and the rheumatologist: which patients are at risk and how can pcp be prevented? Curr Rheumatol Rep 2017; 19: 35, doi: 10.1007/s11926-017-0664-6.
19. Wu L, Wang $X$, Chen F, Lv X, Sun W, Guo $Y$, et al. T cell subsets and immunoglobulin $G$ levels are associated with the infection status of systemic lupus erythematosus patients. Braz J Med Biol Res 2017; 51: e4547, doi: 10.1590/1414431X20154547.

20. Nagata S. Apoptosis and clearance of apoptotic cells. Annu Rev Immunol 2018; 36: 489-517, doi: 10.1146/annurevimmunol-042617-053010.

21. Littlejohn E, Marder W, Lewis E, Francis S, Jackish J, McCune WJ, et al. The ratio of erythrocyte sedimentation rate to C-reactive protein is useful in distinguishing infection from flare in systemic lupus erythematosus patients presenting with fever. Lupus 2018; 27: 1123-1129, doi: 10.1177/ 0961203318763732.

22. Echeverri A, Naranjo-Escobar J, Posso-Osorio I, AguirreValencia D, Zambrano D, Castaño GL, et al. Neutrophil CD64 expression, procalcitonin and presepsin are useful to differentiate infections from flares in SLE patients with SIRS. Lupus 2018; 27: 1130-1139, doi: 10.1177/096120331876 3740.

23. Liu LN, Wang P, Guan SY, Li XM, Li BZ, Leng RX, et al. Comparison of plasma/serum levels of procalcitonin between infection and febrile disease flare in patients with systemic lupus erythematosus: a meta-analysis. Rheumatol Int 2017; 37: 1991-1998, doi: 10.1007/s00296-017-3827-x. 